\title{
Elaborative Feedback to Enhance Online Second Language Reading Comprehension
}

\author{
Andy Bown ${ }^{1}$ \\ ${ }^{1}$ University of Tasmania, Australia \\ Corresponding: Andy Bown, University of Tasmania, Australia. E-mail: andy.bown@utas.edu.au
}

Received: October 10, 2017 Accepted: November 6, 2017 Online Published: November 9, 2017

doi: 10.5539/elt.v10n12p164

URL: http://doi.org/10.5539/elt.v10n12p164

\begin{abstract}
Many higher education students across the world are studying in situations where a high proportion of the academic materials they encounter are online reading texts written in their second language. While the online medium presents a number of challenges to L2 readers, it also enables the provision of a range of support mechanisms, such as instant feedback. This quasi-experimental study investigated the use of two types of feedback, elaborative and knowledge of response, and compares their effectiveness for enhancing online second language reading comprehension. The participants were 113 Emirati students of L2 English at a higher education college in the United Arab Emirates. Data were collected using a pre-test and a post-test measure of reading comprehension and an online reading comprehension exercise containing either elaborative or knowledge of response feedback. The results of the quasi-experiment showed no significant difference between the effects of the two feedback types on comprehension of an online reading text for the sample as a whole. Equally, for the high-proficiency readers, feedback type had no significant effect on text comprehension. However, with regard to the low-proficiency readers, those receiving elaborative feedback performed significantly better on the post-test than those who received knowledge of response feedback. The findings suggest that elaborative feedback can enhance online L2 reading comprehension but that it needs to be tailored specifically to the needs of the $\mathrm{L} 2$ readers it is intended to support.
\end{abstract}

Keywords: online reading, second language reading, computer-assisted language learning, elaborative feedback, sociocultural theory

\section{Introduction}

\subsection{Background}

The ability to read at least one language is undoubtedly a vital skill for success in today's world. With regard to second language (L2) learners, strong reading skills can assist in the development of other language skills, whereas poor L2 reading skills can hamper academic progress (Anderson, 2003). This is particularly the case in academic contexts where $\mathrm{L} 2$ texts account for a substantial proportion of the academic materials encountered by students, as is the case in many higher education institutions in Arabian Gulf countries, such as the United Arab Emirates (Donaghue \& Thompson, 2014). This situation presents a challenge to L2 learners and their teachers, given the complex nature of L2 reading proficiency, which, as shown below, depends on the effective use of a range of knowledge sources. These sources include L2 knowledge, L1 literacy, and reading comprehension strategies (Bernhardt, 2011). Testament to the magnitude and importance of this challenge is the amount of attention that L2 reading instruction has received from researchers in the field of applied linguistics and language education (Han, Anderson, \& Freeman, 2009).

In recent years, the ever-increasing use of the Internet has had an impact on the reading habits of students in higher education, as the use of online texts is now a key component of tertiary education courses across the world (Ketabi, Ghavamnia, \& Rezazedah, 2012). While the availability of internet connections and compatible devices has increased L2 readers' access to online texts, it has also brought with it new challenges related to the different reading comprehension skills and strategies that are necessary in online environments (Park, Yang, \& Hsieh, 2014). As Konishi (2003) notes, navigation strategies, which include clicking and scrolling, are key to successful online reading but are not required when reading printed texts.

However, while the online medium presents certain challenges to L2 readers, it also makes possible a variety of 
support mechanisms that may both facilitate and enhance comprehension. One such mechanism is elaborative feedback, which can be incorporated into online reading exercises to provide additional guidance and support to L2 readers (Murphy, 2007, 2010). Previous research into the effectiveness of elaborative feedback to enhance L2 reading comprehension has been largely inconclusive (Bown, 2006; Murphy, 2007, 2010). However, it has been shown to significantly improve comprehension when used in combination with oral pair-work activities (Murphy, 2007) and to support quality interaction between L2 readers when used in conjunction with text-based computer-mediated discussion (Murphy, 2010).

This study investigates whether elaborative feedback incorporated into an online academic reading exercise is more effective than simple, knowledge of response feedback in enhancing L2 reading comprehension. It also examines whether the effect of elaborative feedback on comprehension differs with L2 reading proficiency.

\subsection{Literature Review}

\subsubsection{Types of Computer-assisted Feedback}

Previous studies in the field of computer-assisted learning have supported the use of questions with feedback as an effective element of text-based learning (Clariana \& Koul, 2006), with three main types of feedback being identified (Clariana, 2000; Murphy, 2010). Knowledge of response feedback informs the learner whether their answer is correct or incorrect, knowledge of correct response feedback indicates the correct answer, while elaborative feedback provides additional information to explain the reasons for a response being correct or incorrect or to guide the learner towards a correct response (Murphy, 2007). A common form of elaborative feedback is answer until correct feedback, in which the learner is guided to respond until the correct answer is determined.

With regard to the relative effectiveness of different feedback types, previous studies have been inconclusive. Adams and Strickland (2012) investigated the use of knowledge of response feedback, knowledge of correct response feedback, and no feedback, with 70 students of computer literacy. They found no difference in the effectiveness of the three feedback strategies. Bangert-Drowns, Kulik, Kulik and Morgan (1991) undertook a meta-analysis of 40 studies and concluded that knowledge of response was the least effective form of feedback, and was even less effective than no feedback at all. The most effective feedback types were found to be answer until correct feedback and elaborative feedback. Bangert-Drowns et al. also found that the provision of more information in feedback increased its effectiveness. In contrast, Clariana (1993) reviewed 30 studies and found that all types of feedback were more effective than the provision of no feedback. However, he found no significant difference in the effectiveness of different feedback types. It should be noted that both meta-analyses were conducted on a range of studies that were not specifically related to L2 acquisition or L2 reading.

\subsubsection{Computer-assisted Feedback and L2 Acquisition}

The question of which type of computer-assisted feedback is most effective for supporting different aspects of L2 acquisition has been the focus of numerous studies (Bown, 2006; Brandl, 1995; Murphy, 2007, 2010; Nagata, 1993, 1996; Van der Linden, 1993), but remains largely unanswered. Van der Linden (1993) investigated the effectiveness of elaborative feedback within computer-based grammar exercises with 23 learners of L2 French. She found that individual differences among learners affected the usefulness of the feedback. Similarly, Brandl (1995) studied the preferences for different types of error correction feedback of 21 high- and low-achievement learners of L2 German while completing computer-based grammar exercises. The learners were presented with knowledge of response, knowledge of correct response, elaborative, and show error feedback, which highlighted any errors in a learner's response. Brandl found differences in the use of feedback among the groups, with the high-achievement learners checking the feedback more often than their low-achievement counterparts. Furthermore, the low-achievement students were more likely to use the feedback to look up the correct answers, whereas the high-achievement learners tended to attempt to find the answers themselves.

The most effective feedback type to support L2 reading comprehension has also been investigated, again with mixed results. Murphy (2007) explored the use of elaborative feedback to promote L2 reading comprehension with 407 first-year students of L2 English at a Japanese university. The learners were divided into high- and low-proficiency groups, based on their membership of pre-existing English classes, and then randomly assigned to receive either elaborative feedback or knowledge of correct response feedback when completing an online reading comprehension exercise. Furthermore, they were randomly assigned to work either individually or in pairs as they completed the exercise. Following the treatment, all participants worked independently to complete a follow-up reading comprehension exercise, which tested comprehension of the same content areas covered in the first exercise, in order to measure their comprehension of the text. Murphy found that elaborative feedback was not significantly more effective than knowledge of correct response feedback. He also found no significant 
interaction between L2 English proficiency level and feedback type. In a second study, Murphy (2010) compared the use of elaborative feedback and knowledge of correct response feedback with 425 L2 learners of English at a Japanese university. The learners were assigned to either the low- or high-proficiency group according to their results on an English proficiency test. All the participants were randomly assigned to receive either elaborative feedback or knowledge of correct response feedback while completing an online reading comprehension exercise in pairs with a partner of the same proficiency level. Murphy found that those who received elaborative feedback scored significantly higher on a follow-up test based on the same reading text than did those who received knowledge of correct response feedback. He also found no significant interaction between feedback type and proficiency level. However, in both these studies, it is noteworthy that the assignment of students to either the high- or low-proficiency group was based on L2 English proficiency levels, and that no pre-test was utilized to control specifically for pre-existing levels of $\mathrm{L} 2$ reading comprehension.

\subsubsection{Feedback as Scaffolding for L2 Reading Comprehension}

Elaborative feedback can be used to guide and direct the L2 reader, thereby providing additional support. From a sociocultural view of L2 acquisition, this support can be considered as a form of scaffolding, the "process of supportive dialogue which directs the attention of the learner to key features of the environment, and which prompts them through successive steps of a problem" (Mitchell, Myles, \& Marsden, 2013, p. 222). For scaffolding to be effective, it should be carefully targeted at the needs of the learners working within their zone of proximal development (Gibbons, 2015). With regard to L2 reading, this suggests that, when writing elaborative feedback to support learners working alone on a reading comprehension exercise, the instructor/designer should consider (at least) the following: the L2 reading proficiency level of the readers, the difficulty level of the reading task, and models of L2 reading comprehension. With regard to L2 reading proficiency and task difficulty, carefully targeted elaborative feedback that is tailored to the needs of a low-proficiency reader working on a comprehension exercise may not, therefore, correspond to the needs of a higher-proficiency reader.

Concerning L2 reading models, Bernhardt's (2011) Compensatory Model of Second Language Reading predicts that $50 \%$ of the variance in L2 reading can be explained by first language (L1) literacy and L2 language knowledge. The remaining $50 \%$ of the variance is explained by other factors, which include reading comprehension strategies, engagement, background knowledge, interest and motivation. McNeil (2012) extends Bernhardt's Compensatory Model by predicting the contributions of strategic knowledge and background knowledge to L2 reading performance. In his extended model, L1 literacy, L2 knowledge, background knowledge and strategic knowledge are predicted to account for $75 \%$ of the variance in L2 reading. Furthermore, the relative contributions of these knowledge sources are predicted to vary with proficiency level. Bernhardt asserts that an L2 reader relies on these different knowledge sources according to need whenever a reading difficulty is encountered. Further, through compensatory processing, a weakness in one knowledge source can be compensated for by greater use of another knowledge source. For scaffolding, in the form of elaborative feedback, to be effective in enhancing reading comprehension, it should make additional knowledge available for compensatory processing by the reader when a comprehension difficulty is encountered.

In the light of the above review of the literature, this current study attempted to build on previous research into the use of elaborative feedback to enhance L2 reading comprehension by employing a sociocultural approach, in which feedback is viewed as a form of scaffolding that needs to be tailored to the individual needs of learners (Gibbons, 2015). In this regard, unlike Murphy $(2007,2010)$, a pre-test measure of L2 reading comprehension was employed to control for pre-existing reading ability.

\subsection{Hypotheses}

The following hypotheses were tested in this study.

Hypothesis 1: The elaborative feedback will be more effective than knowledge of response feedback in enhancing comprehension of the online reading text.

Hypothesis 2: The effect of the elaborative feedback on comprehension of the online reading text will differ between the lower- and higher-proficiency groups.

\section{Method}

A quasi-experimental design was employed for this study. This involved the collection of quantitative data, in the form of pre- and post-test results, from members of six pre-existing classes. 


\subsection{Participants}

The participants were 113 male Emirati students of L2 English aged between 20 and 26. They were in their second or fourth semester of study towards a Higher Diploma or Bachelor's Degree in either Information Technology and Business or Mechatronics at Ras Al Khaimah Men's College, one of the Higher Colleges of Technology in the United Arab Emirates. As a graduation requirement, all the participants were required to achieve a Band 5.5 in the Academic Module of the International English Language Testing System (IELTS), which reflects a proficiency level between that of a modest and a competent user of English (IELTS, 2017). They were due to take the IELTS examination at the end of their fourth semester of study. The participants were all competent computer users, having successfully completed a course in computer literacy as a requirement of program entry. Furthermore, the use of a laptop or desktop computer was a regular feature of all their courses.

\subsection{Sampling and Assignment}

The participants were drawn from six pre-existing English classes, which contained the entire cohort of second and fourth semester students at the college. Two second-semester classes and one fourth-semester class contained students majoring in Information Technology and Business, and the same number of second and fourth-semester classes consisted of Mechatronics students. The participants were randomly assigned to one of two treatment groups, Group 1, who would receive elaborative feedback, and Group 2, who would receive knowledge of response feedback. The pre-test was completed by 104 of the 113 participants, while 9 were absent. For the post-test, 99 participants completed the test, one failed to submit his responses, and 13 were absent. In total, 92 participants, 47 from Group 1 and 45 from Group 2, completed both the pre-test and the post-test.

\subsection{Instruments and Materials}

Two online reading tests and one online reading comprehension exercise were designed to be delivered to the participants via Blackboard (www.blackboard.com), the learning management system employed by the institution. It was intended that the participants' familiarity with Blackboard would help minimize any difficulties they might face in accessing and completing the tests and comprehension exercise.

The pre-test, which consisted of 40 items, was adapted for online delivery from a published IELTS Academic Module reading practice test (O'Sullivan \& Lindeck, 2000, pp. 58-68). The 40 items, of which 25 were multiple choice and 15 were short-answer questions, were based on three reading texts with a combined length of 1893 words. The test had a time limit of 60 minutes and was password protected so that the participants could not access it before their assigned test time.

The post-test, which consisted of 14 multiple-choice items, was prepared for online delivery and based on one section of an IELTS Academic Module reading practice test (Gould \& Clutterbuck, 2004, pp. 30-33). The text was 770 words in length and the time limit for the test, which was also password protected, was 20 minutes.

The reading comprehension exercise was developed for online delivery and was based on the same text used in the post-test. The questions were different from those in the post-test, however, each question in the reading comprehension exercise was written to focus on comprehension of the same part of the text as the corresponding question in the post-test. Two versions of the reading comprehension exercise were created. One version, which was designed for the Group 1, contained elaborative feedback to provide the reader with additional guidance and support. The other version, which was intended for delivery to Group 2, contained knowledge of response feedback, which simply informed the reader whether their response was correct or incorrect. For example, following an incorrect response to Question 11, the elaborative feedback would provide the following support: "Incorrect. Read paragraph 3 again. What type of menu offers the same dishes every day? What type offers variation?" In contrast, the knowledge of response feedback would state simply "Incorrect". Both feedback types were answer until correct feedback, which allowed the reader multiple attempts to answer each question correctly.

\subsection{Procedures}

In the first week of the study, the researcher visited all six English classes and demonstrated how to complete the pre-test, which was delivered using Blackboard. This was intended to ensure consistency in the delivery of the test and the instructions provided. Once the password to access the test was issued to the participants, they had 60 minutes to complete and submit the pre-test, which was scored automatically by the Quiz tool in Blackboard.

In the second week, the researcher visited the classes again to deliver the reading comprehension exercise via Blackboard. Group 1 received the version containing elaborative feedback, whereas Group 2 received the version containing simple, knowledge of response feedback. Both groups were given 30 minutes to complete the reading comprehension exercise, after which they were given the password to access the post-test, which lasted 
20 minutes.

\subsection{Variables}

For Hypotheses 1 and 2, the independent variable was the type of feedback received; the two levels were 'elaborative feedback' and 'knowledge of response feedback'. The dependent variable was online reading comprehension, which was measured by the post-test. The co-variate was pre-existing online reading comprehension, which was measured by the pre-test.

\section{Data Analysis and Results}

In total, 92 participants completed both the pre-test and the post-test, 47 from Group 1 and 45 from Group 2. An ANCOVA was conducted to assess the significance of differences between the mean scores of the two groups on the post-test, while controlling for pre-existing differences in reading comprehension prior to the treatment, as measured by the pre-test.

The results of the ANCOVA indicated that, after controlling for performance on the pre-test, there was no significant difference in mean scores on the post-test between Group $1(M=7.09, S D=2.17)$ and Group $2(M=6.44$, $S D=2.38), F(1,89)=1.39, p=.241$. The effect size was small (partial eta squared=.015), with $1.5 \%$ of the variance in scores on the post-test accounted for by the treatment condition (elaborative feedback or knowledge of response feedback).

The results of the ANCOVA reject Hypothesis 1, which states that elaborative feedback will be more effective than knowledge of response feedback in enhancing comprehension of an online reading text.

In order to test Hypothesis 2, low- and high-proficiency sub-groups of both Group 1 and Group 2 were formed, based on the results of the pre-test. These groups were formed for the purposes of data analysis alone and had no direct impact on the participants.

In line with Bachman (2004) and McNeil (2012), those among the 92 participants who scored in the top third on the pre-test were placed into the high-proficiency group, while those who scored in the bottom third formed the low-proficiency group. The participants scoring in the middle third were excluded, as were those participants who had not completed both the pre-test and the post-test. In practice, the high-proficiency group consisted of 34 participants $(37.00 \%$ of the population), whereas the low-proficiency group comprised 31 participants $(33.70 \%$ of the population). This decision was taken in order to ensure that the sub-groups to be formed from these two groups (described below) would have a minimum of 15 participants, as recommended by Dornyei (2007).

An independent samples $t$-test was conducted to test for differences in the mean scores of the high- and low-proficiency groups on the pre-test. There was a significant difference in the scores of the high-proficiency group $(M=18.71, S D=2.48)$ and the low-proficiency group $(M=9.39, S D=1.50), t(63)=18.11, p=.000$. The effect size (eta squared $=.839$ ) was very large, with $83.9 \%$ of the variance in scores on the pre-test explained by the proficiency level. This suggests that the assignment of the participants into high- and low-proficiency groups was effective.

The high-proficiency group was divided into two sub-groups, according to the participants' membership of either Group 1 or Group 2. The high-proficiency sub-group of Group 1 (Group 1H) consisted of 19 participants, while the corresponding sub-group of Group 2 (Group $2 \mathrm{H}$ ) comprised 15 participants. The low-proficiency group was sub-divided in a similar manner, with the low-proficiency sub-groups of Group 1 (Group 1L) and Group 2 (Group 2L) containing 16 participants and 15 participants respectively.

A second ANCOVA was conducted to test for differences between the mean scores of Group $1 \mathrm{H}$ and Group $2 \mathrm{H}$ on the post-test, while controlling for pre-existing differences in reading comprehension prior to the treatment, as measured by the pre-test.

The results of the ANCOVA indicated that, after controlling for performance on the pre-test, there was no significant difference in mean scores on the post-test between Group $1 \mathrm{H}(M=8.68, S D=1.77)$ and Group $2 \mathrm{H}$ $(M=8.20, S D=2.08), F(1,31)=.52, p=.476$. The effect size was small (partial eta squared=.017), with $1.7 \%$ of the variance in scores on the post-test accounted for by the treatment condition (elaborative feedback or knowledge of response feedback).

A third ANCOVA was conducted to assess the significance of differences between the mean scores of Group 1L and Group $2 \mathrm{~L}$ on the post-test, while controlling for pre-existing differences in reading comprehension prior to the treatment, as measured by the pre-test.

The results of the ANCOVA indicated that, after controlling for scores obtained on the pre-test, there was a significant difference in mean scores on the post-test between Group $1 \mathrm{~L}(M=6.13, S D=2.06)$ and Group $2 \mathrm{~L}$ 
$(M=4.87, S D=1.55), F(1,28)=4.36, p=.046$. The effect size was moderate to large (partial eta squared=.135) with $13.5 \%$ of the variance in scores on the post-test accounted for by the treatment condition (elaborative feedback or knowledge of response feedback).

The results of the second and third ANCOVA support Hypothesis 2, which states that the effect of the elaborative feedback on the comprehension of the online reading text will differ between the lower- and higher-proficiency groups.

\section{Discussion}

With regard to Hypothesis 1, the results of the quasi-experiment showed no significant effect for feedback type on comprehension of the online L2 reading text. Although Group 1, who received elaborative feedback, scored higher on the post-test than Group 2, who received knowledge of response feedback, the difference in mean scores was not significant. This finding is similar to that of Murphy (2007), who found no significant difference between the effects of elaborative feedback and knowledge of correct response feedback on L2 reading comprehension.

Regarding Hypothesis 2, the results of the second ANCOVA showed no significant effect for feedback type on online L2 reading comprehension for the higher-proficiency learners. However, the results of the third ANCOVA revealed that, for the lower-proficiency readers, elaborative feedback was significantly more effective at enhancing comprehension of the online L2 reading text than was knowledge of response feedback. This supports Hypothesis 2, which states that the effect of the elaborative feedback on comprehension of the online reading text will differ between the lower- and higher-proficiency groups. This differs from the findings of Murphy (2007), who found no significant interaction between feedback type and proficiency level. However, in Murphy's study, no pre-test was employed to measure L2 reading comprehension prior to the intervention. In this study, the use of a pre-test enabled the use of ANCOVA to control for pre-existing online L2 reading comprehension, which was considered to be an important confounding variable in this study. It also allowed the formation of low- and high-proficiency sub-groups, following Bachman (2004).

From a sociocultural perspective, the findings of this study support the view that elaborative feedback, as a form of scaffolding, should be carefully targeted at the needs of the learner(s). With this in mind, it is perhaps not surprising that the same elaborative feedback that was able to enhance the text comprehension of the lower-proficiency learners was less effective in supporting the higher-proficiency ones. Had the feedback been targeted at higher-level learners, the results may have been different.

The Compensatory Model of Second Language Reading (Bernhardt, 2011; McNeil, 2012) may also help explain the results of the second and third ANCOVA. For the elaborative feedback to be useful in enhancing L2 reading comprehension, it needed to provide additional compensatory processing power to the reader by supplementing existing knowledge sources. While this may have been the case for the lower-proficiency readers, the guidance and information within the elaborative feedback may not have added significantly to the existing knowledge sources of the higher-proficiency readers.

\section{Limitations of the Study}

This current study was limited by the relatively small sample sizes involved. Although the size of each group and sub-group involved met the minimum requirements for a quasi-experimental intervention study (Dornyei, 2007), a larger sample size drawn from a more diverse population would have strengthened the findings of the study. In addition, the use of supplementary data collection techniques, such as interviews, questionnaires, and think-aloud protocols, would have helped further explain how elaborative feedback affects online L2 reading comprehension.

\section{Conclusion}

Overall, the findings from this study support the use of elaborative feedback within online L2 reading comprehension exercises. In this study, the elaborative feedback only significantly enhanced the L2 online reading comprehension of the lower-proficiency readers when compared with simple, knowledge of response feedback. However, this may have been due to the characteristics of the feedback provided. The results do suggest, however, that elaborative feedback which can enhance the comprehension of L2 readers of a certain proficiency level may be less useful for readers at a different level. This has an important implication for material designers and classroom teachers who are considering the use of elaborative feedback to support L2 reading comprehension. In situations where L2 reading levels are largely homogeneous, elaborative feedback might be a useful means of supporting the L2 reading comprehension of a large percentage of the learners. In more heterogeneous contexts, elaborative feedback might be used to provide additional support to specific groups of learners. In both scenarios, classroom teachers could use resources, such as the English Profile 
(http://www.englishprofile.org/), to help them predict which grammar or vocabulary items within a reading text might pose comprehension difficulties for their students. This information could then guide the development of elaborative feedback to support students as they read the text.

Future research could use a mixed-methods approach to investigate the factors which influence the effectiveness of elaborative feedback and its use by L2 readers.

\section{References}

Adams, R. H., \& Strickland, J. (2012). The effects of computer-assisted feedback strategies in technology education: A comparison of learning. Journal of Educational Technology Systems, 40(2), 211-223. https://doi.org/10.2190/ET.40.2.i

Anderson, N. J. (2003). Scrolling, clicking, and reading English: Online reading strategies in a second/foreign language. The Reading Matrix, 3(3), 1-33.

Bachman, L. (2004). Statistical Analyses for Language Assessment. Cambridge University Press: Cambridge. https://doi.org/10.1017/CBO9780511667350

Bangert-Drowns, R. L., Kulik, C. C., Kulik, J. A., \& Morgan, M. (1991). The instructional effect of feedback in test-like events. Review of Educational Research, 61, 213-238. https://doi.org/10.3102/00346543061002213

Bernhardt, E. B. (2011). Understanding advanced second-language reading. New York: Routledge.

Bown, A. (2006). The usefulness of guided feedback in a web-based IELTS reading programme for Arab learners (Master's thesis). Asian EFL Journal. Retrieved from http://asian-efl-journal.com/ Thesis_Bown_2006.pdf

Brandl, K. K. (1995). Strong and weak students' preferences for error feedback options and responses. The Modern Language Journal, 79, 194-211. https://doi.org/10.1111/j.1540-4781.1995.tb05431.x

Clariana, R. B. (1993). A review of multiple-try feedback in traditional and computer-based instruction. Journal of Computer-Based Instruction, 20(3), 67-74.

Clariana, R. B. (2000). Feedback in computer-assisted learning. NETg University of Limerick Lecture Series. Retrieved from http://www.personal.psu.edu/faculty/r/b/rbc4/NETg.htm

Clariana, R. B., \& Koul, R. (2006). The effects of different forms of feedback on fuzzy and verbatim memory of science principles. British Journal of Educational Psychology, 76, 259-270. https://doi.org/10.1348/000709905X39134

Donaghue, H., \& Thompson, J. (2014). Talking about reading: Students' perspectives. In H. Emery, \& N. Moore (Eds.), Teaching, learning and researching reading in EFL (pp. 9-26). Dubai: TESOL Arabia.

Dornyei, Z. (2007). Research methods in applied linguistics. Oxford: Oxford University Press.

Gibbons, P. (2015). Scaffolding language scaffolding learning: Teaching English language learners in the mainstream classroom (2nd ed.). Portsmouth, NH: Heinemann.

Gould, P., \& Clutterbuck, M. (2004). Focusing on IELTS: Academic practice tests. Sydney: NCELTR.

Han, Z., Anderson, N. J., \& Freeman, D. (2009). Introduction: Crossing the boundaries. In Z. Han, \& N. J. Anderson (Eds.), Second language reading research and instruction: Crossing the boundaries (pp. 1-13). Michigan: Michigan University Press. https://doi.org/10.1057/9780230101937_1

International English Language Testing System (IELTS). (2017). How IELTS is scored. Retrieved from https://www.ielts.org/about-the-test/how-ielts-is-scored

Ketabi, S., Ghavamnia, M., \& Rezazadeh, M. (2012). Hypermedia reading strategies used by Persian graduate students in TEFL: A think-aloud study. The Reading Matrix, 12(1), 39-49.

Konishi, M. (2003). Strategies for reading hypertext by Japanese ESL learners. The Reading Matrix, 3(3), 97-119.

McNeil, L. (2012). Extending the compensatory model of second language reading. System, 40, 64-76. https://doi.org/10.1016/j.system.2012.01.011

Mitchell R., Myles, F., \& Marsden, E. (2013). Second Language Learning Theories (3rd ed.). London: Routledge

Murphy, P. (2007). Reading comprehension exercises online: The effects of feedback, proficiency and interaction. Language Learning \& Technology, 11(3), 107-129. Retrieved from http://lt.msu.edu/ vol11num3/murphy/default.html 
Murphy, P. (2010). Web-based collaborative reading exercises for learners in remote locations: The effects of computer-mediated feedback and interaction via computer-mediated communication. ReCALL, 22, 112-134. https://doi.org/10.1017/S0958344010000030

Nagata, N. (1993). Intelligent computer feedback for second language instruction. The Modern Language Journal, 77, 330-339. https://doi.org/10.1111/j.1540-4781.1993.tb01980.x

Nagata, N. (1996). Computer vs. workshop instruction in second language acquisition. CALICO Journal, 14, 53-75.

O’Sullivan, K., \& Lindeck, J. (2000) Focusing on IELTS: Reading and writing skills. Sydney: NCELTR.

Park, J., Yang, J., \& Hsieh, Y. C. (2014). University level second language readers' online reading and comprehension strategies. Language Learning \& Technology, 18(3), 148-172. Retrieved from http://1lt.msu.edu/issues/october2014/parkyanghsieh.pdf

Van der Linden, E. (1993). Does feedback enhance computer-assisted language learning? Computers and Education, 21, 61-65. https://doi.org/10.1016/0360-1315(93)90048-N

\section{Copyrights}

Copyright for this article is retained by the author(s), with first publication rights granted to the journal.

This is an open-access article distributed under the terms and conditions of the Creative Commons Attribution license (http://creativecommons.org/licenses/by/4.0/). 